\title{
The 2013 Earthquake Series in the Southern Vienna Basin: location
}

\author{
M.-T. Apoloner ${ }^{1}$, G. Bokelmann ${ }^{1}$, I. Bianchi ${ }^{1}$, E. Brückl ${ }^{2}$, H. Hausmann ${ }^{3}$, S. Mertl ${ }^{4}$, and R. Meurers ${ }^{3}$ \\ ${ }^{1}$ Department of Meteorology and Geophysics, University of Vienna, Vienna, Austria \\ ${ }^{2}$ Department of Geodesy and Geoinformation, Vienna University of Technology, Vienna, Austria \\ ${ }^{3}$ Zentralanstalt für Meteorologie und Geodynamik, Vienna, Austria \\ ${ }^{4}$ Mertl Research GmbH, Vienna, Austria
}

Correspondence to: M.-T. Apoloner (maria-theresia.apoloner@univie.ac.at)

Received: 13 June 2014 - Revised: 22 July 2014 - Accepted: 24 July 2014 - Published: 27 August 2014

\begin{abstract}
Eastern Austria is a region of low to moderate seismicity, and hence the seismological network coverage is relatively sparse. Nevertheless accurate earthquake location is very important, as the area is one of the most densely populated and most developed areas in Austria.

In 2013 a series of earthquakes with magnitudes up to 4.2 was recorded in the Southern Vienna Basin. With portable broadband, semi-permanent, and permanent installed seismic sensors from different institutions it was possible to record the main- and aftershocks with an unusual multitude of closeby seismic stations.

In this study we combine records from all available stations up to $240 \mathrm{~km}$ distance in one dataset. First, we stabilize the location with three stations deployed in the epicentral area. The higher network density moves the location of smaller magnitude events closer to the main shocks, with respect to preliminary locations achieved by permanent and semi-permanent networks. Then we locate with NonLinLoc using consistent picks, a 3-D velocity model and apply station corrections. This second approach results in stable epicenters, for limited and even changing station availability.

This dataset can then be inspected more closely for the presence of regional phases, which then can be used for more accurate localizations and especially depth estimation. Further research will address directivity effects and the asymmetry in earthquake intensity observed throughout the area, using double differences and cross-correlations.
\end{abstract}

\section{Introduction}

The study area is situated at the transition of the Eastern Alps to the Pannonian Basin and the Western Carpathians. The Vienna Basin is, due to the vicinity to Vienna, one of the most densely populated and developed areas in the region.

Instrumentally recorded seismicity in the area is moderate, with a maximum registered magnitude of around 5. The Vienna Basin Fault System occasionally shows earthquakes with magnitudes larger than 4, for example in 1938 close to Ebreichsdorf one event with a magnitude of 5.0. Historical records (e.g., Gutdeutsch et al., 1987) and paleoseismicity (e.g., Hintersberger et al., 2010) indicate that even stronger earthquakes occur, more infrequently.

The Austrian seismological network is built of very high quality stations. However, due to large inter-station distances the allocation of an events to a fault is not always definite. Earthquake location and depth estimation accuracy can be increased with different approaches: additional seismic stations, particularly close to the epicenter, are the easiest way of improvement. As most location techniques are strongly dependent on the velocity model, the use of a regionally adapted model has a significant impact. The location technique itself has a big influence as well, in particular as seismic data and the velocity model enter in different ways.

In this article, we show an earthquake series south of Vienna in fall 2013, and which steps can be taken to improve and stabilize location. We deployed additional stations and collected all available data up to $240 \mathrm{~km}$ distance to form a comprehensive dataset. We use two different location techniques with two distinct velocity models.

This article illustrates the change in location and tries to allocate the earthquakes to known faults. 


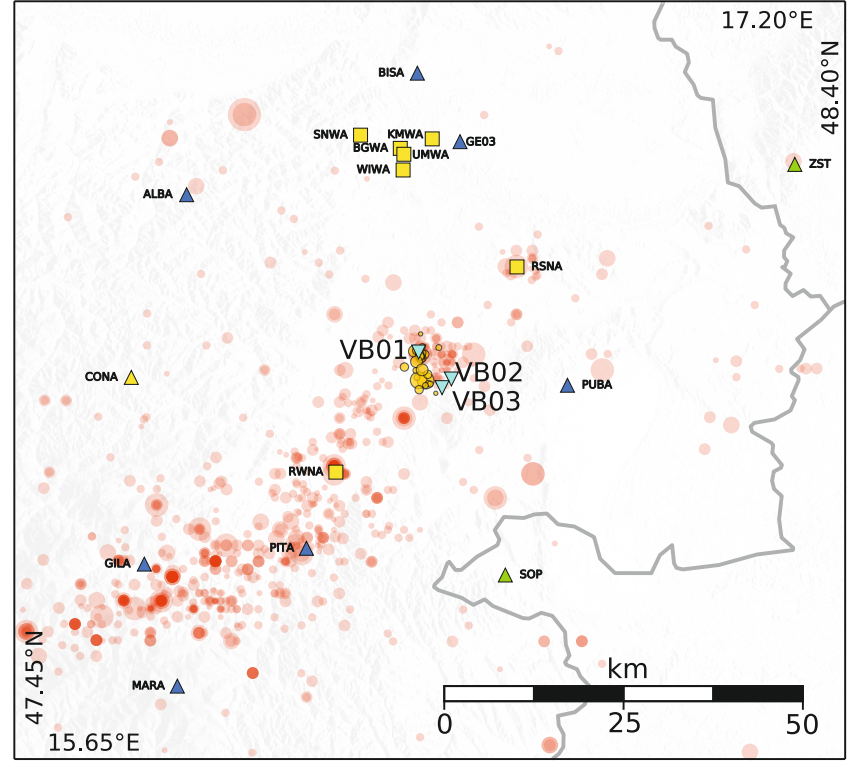

\begin{tabular}{|ll}
$\triangle$ & Intl. Observatories via ORFEUS \\
$\triangle$ & ZAMG: Broadband \\
$\square$ & ZAMG: Strongmotion \\
$\triangle$ & Vienna University of Technology \\
$\nabla$ & University of Vienna \\
Austrian Earthquake Catalog \\
Earthquake Series Fall 2013
\end{tabular}

Figure 1. Local station networks and earthquake distribution.

\section{Dataset}

\subsection{Seismicity}

In fall 2013 an earthquake series was recorded in the Southern Vienna Basin close to Ebreichsdorf. Two main shocks with a local magnitude of 4.2 as well as about 30 aftershocks with magnitudes below 3.0 were observed. Although in 2000 a similar earthquake swarm was registered, with an epicentral distance to the closest permanent station of $20 \mathrm{~km}$, hypocentral parameters can be only constrained within limits. This time the events were recorded by a multitude of networks as shown in Fig. 1.

\subsection{Velocity models}

We used two velocity models for this investigation. The global IASP91 (Kennett, 1991) 1-D velocity model, which is used for event location in the ZAMG bulletin. The 3-D Pand S-velocity models by Behm et al. (2007a, b), which are available for Eastern Austria, were also used.

\subsection{Seismic stations}

The Zentralanstalt für Meteorologie und Geodynamik (ZAMG) operates a seismic network of permanent

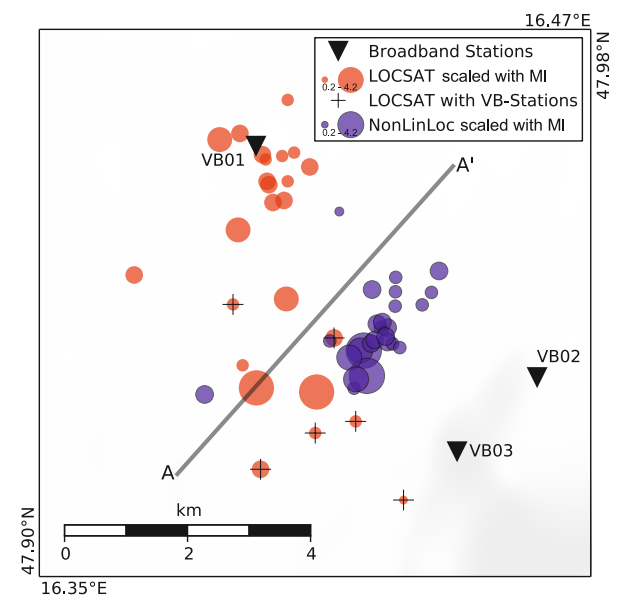

Figure 2. Comparison of epicentral locations calculated with different approaches. Profile A parallel to fault direction by Peresson and Decker (1997).

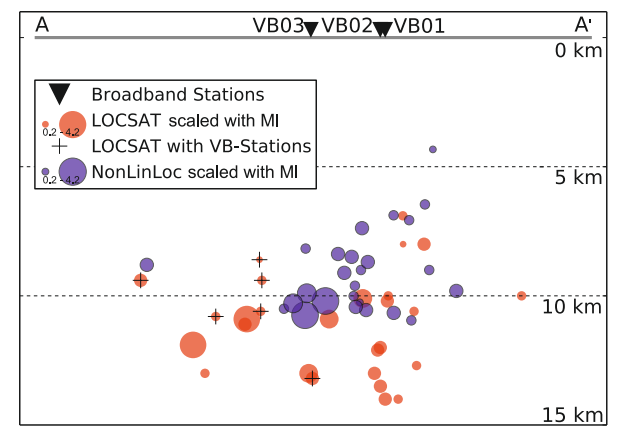

Figure 3. Earthquake depth distribution along profile A (see Fig. 2 for details).

broadband and strong motion stations in Austria. As part of the ALPAACT Project (Mertl and Brückl, 2010), by the Technical University of Vienna (TU) 10 temporary seismic stations record seismic data in and around the Vienna Basin. Also, seismic records of the national networks surrounding Austria have been obtained via ORFEUS web service. Supplementary data from the nuclear power plant monitoring stations in Hungary was made available by GeoRisk Earthquake Engineering. After the second main shock, the University of Vienna deployed three seismic broadband stations (VB01, VB02 and VB03) as close as possible to the epicenters of the magnitude 4.2 events, as given in the ZAMG bulletin. We assembled all available data from the stations in above-mentioned networks to a comprehensive dataset for this study. We used stations up to $240 \mathrm{~km}$ distance, as the 3-D model has limited coverage. 
Table 1. Hypocentral parameters with LOCSAT and NonLinLoc, events located with LOCSAT using VB01, VB02 and VB03 are marked with $*$ at the beginning of the line.

\begin{tabular}{|c|c|c|c|c|c|c|c|}
\hline \multirow{2}{*}{$\begin{array}{l}\text { Origin Time (CEST) } \\
\text { DD.MM.YY HH:MM }\end{array}$} & \multirow[b]{2}{*}{ Ml } & \multicolumn{3}{|c|}{ LOCSAT } & \multicolumn{3}{|c|}{ NonLinLoc } \\
\hline & & Lon & Lat & Depth & Lon & Lat & Depth \\
\hline $4.9 .1311: 00$ & 1.9 & 16.4088 & 47.9599 & 8.0 & 16.4369 & 47.9447 & 9.8 \\
\hline $20.9 .1302: 06$ & 4.2 & 16.4103 & 47.9270 & 10.9 & 16.4206 & 47.9331 & 10.2 \\
\hline $20.9 .1302: 42$ & 1.7 & 16.4032 & 47.9550 & 14.0 & 16.4257 & 47.9364 & 10.6 \\
\hline $20.9 .1302: 44$ & 1.0 & 16.4028 & 47.9615 & 6.9 & 16.4274 & 47.9395 & 6.9 \\
\hline $20.9 .1303: 17$ & 1.3 & 16.4040 & 47.9578 & 14.0 & 16.4242 & 47.9364 & 9.0 \\
\hline $20.9 .1323: 24$ & 1.2 & 16.4054 & 47.9620 & 10.6 & 16.4353 & 47.9416 & 9.0 \\
\hline $24.9 .1313: 53$ & 2.7 & 16.3892 & 47.9639 & 10.1 & 16.4198 & 47.9331 & 9.3 \\
\hline $25.9 .1310: 08$ & 1.7 & 16.3936 & 47.9648 & 12.1 & 16.4222 & 47.9341 & 8.4 \\
\hline $28.9 .1317: 19$ & 0.6 & 16.3942 & 47.9309 & 13.0 & 16.4185 & 47.9276 & 10.5 \\
\hline $1.10 .1323: 54$ & 1.4 & 16.3992 & 47.9610 & 10.0 & 16.4275 & 47.9438 & 6.5 \\
\hline $2.10 .1304: 09$ & 2.0 & 16.3985 & 47.9617 & 10.2 & 16.4230 & 47.9346 & 9.1 \\
\hline $2.10 .1305: 12$ & 1.3 & 16.4040 & 47.9697 & 12.7 & 16.4275 & 47.9417 & 7.1 \\
\hline $2.10 .1305: 26$ & 2.1 & 16.4008 & 47.9547 & 13.0 & 16.4257 & 47.9343 & 8.5 \\
\hline $2.10 .1305: 33$ & 1.8 & 16.3999 & 47.9573 & 12.0 & 16.4234 & 47.9370 & 7.4 \\
\hline $2.10 .1317: 17$ & 4.2 & 16.3972 & 47.9276 & 11.9 & 16.4212 & 47.9294 & 10.8 \\
\hline $2.10 .1319: 38$ & 1.6 & 16.3995 & 47.9578 & 13.5 & 16.4246 & 47.9372 & 8.7 \\
\hline $2.10 .1319: 42$ & 2.8 & 16.3932 & 47.9507 & 10.9 & 16.4174 & 47.9320 & 9.9 \\
\hline $3.10 .1300: 11$ & 0.2 & 16.4008 & 47.9856 & 8.0 & 16.4152 & 47.9534 & 4.3 \\
\hline $3.10 .1300: 18$ & 1.9 & 16.3706 & 47.9441 & 11.1 & 16.3859 & 47.9266 & 8.8 \\
\hline $3.10 .1300: 21$ &.-- & 16.3590 & 47.9386 & 10.0 & 16.3964 & 47.9815 & 9.0 \\
\hline *5.10.13 01:27 & 1.0 & 16.3921 & 47.9398 & 9.4 & 16.4333 & 47.9397 & 10.9 \\
\hline *7.10.13 18:22 & 1.5 & 16.3981 & 47.9157 & 9.4 & 16.4224 & 47.9420 & 10.7 \\
\hline *7.10.13 19:47 & 0.3 & 16.4292 & 47.9112 & 8.6 & 16.4249 & 47.9359 & 10.2 \\
\hline * $13.10 .1323: 26$ & 0.5 & 16.4188 & 47.9227 & 10.6 & 16.4269 & 47.9340 & 10.0 \\
\hline *14.10.13 02:34 & 1.9 & 16.4141 & 47.9349 & 13.2 & 16.4253 & 47.9351 & 10.4 \\
\hline *16.10.13 02:19 & 1.4 & 16.4100 & 47.9210 & 10.8 & 16.4284 & 47.9335 & 9.6 \\
\hline $23.10 .1319: 34$ & 2.6 & 16.4037 & 47.9406 & 13.0 & 16.4189 & 47.9289 & 10.3 \\
\hline $15.11 .1316: 31$ & 0.9 & 16.4348 & 47.9685 & 10.0 & 16.4132 & 47.9345 & 8.2 \\
\hline
\end{tabular}

\section{Hypocenter location}

\subsection{Routine processing with 3 local stations}

The locations given in the bulletin are calculated using the LOCSAT (Nagy, 1996) algorithm with the 1-D velocity model. P- and S-arrivals of the Austrian station network and international stations close to the border are automatically picked and manually reviewed. Besides, the stations PUBA, MARA, SITA and GUWA of the ALPAACT network are included in routine analysis. Six aftershocks were also recorded with the close-by deployed stations VB01, VB02 and VB03. P- and S-picks from those stations were added to the routine processing. The locations using the local stations are marked with $*$ in Table 1 . The mean inter-event distance of the newly located earthquakes decreases from 2.0 to $0.9 \mathrm{~km}$ with inclusion of the VB-stations. The use of these stations also moves the smaller aftershocks closer to the main events.

\subsection{Advanced processing routine with comprehensive consistent dataset}

We picked all station data available to us to compile a consistent arrival dataset. With the program NonLinLoc (Lomax et al., 2000) it was possible to use the 3-D velocity model. However, it does not include small-scale inhomogeneities like the underground beneath a station. This leads to shifts in event location, depending on station availability. This influence was reduced by calculating station corrections in the first location run and applying them in the final run. The improvement in location can be deduced from the mean interevent distance, which is reduced from 1.8 to $1.1 \mathrm{~km}$ after applying station corrections. Especially smaller events with less picks move closer to the rest of the swarm. Events with magnitudes bigger than 2.0 do change their location only negligibly. Hence, it was possible to get stable epicenters even for sparse station configurations. According to Geller (1976) the source radius of the two 4.2 earthquakes was estimated at less than $200 \mathrm{~m}$, based on their $\mathrm{Mb}$ of 3.6, which was taken from the ZAMG Bulletin. 
The final epicenter locations are mostly within an area of $1 \times 2 \mathrm{~km}$ as shown in Fig. 2. The mean hypocentral depth is around $9 \mathrm{~km}$, which is typical for this region as described, e.g. in Lenhardt et al. (2007). This means that the hypocenters are beneath the principal displacement zone of the flower structure which is assumed for this area (Beidinger and Decker, 2011). Furthermore, the epicenters show a southwest to north-east pattern which maps them to the Vienna Basin Fault System. Final locations are listed in Table 1 and are also available in QuakeML format in the digital Supplement related to this article.

\section{Conclusions}

In this study we used a multitude of data available for postprocessing. As expected, a higher network density around the epicenter improves the stability of earthquake locations, even if a global 1-D velocity model is used. With NonLinLoc, 3$\mathrm{D}$ velocity model and station corrections it is possible to get stable epicenters even for changing and sparse station configurations.

Although the events can be associated with a nearby fault, no space-time pattern of the main shocks and their aftershocks can be seen with the methods applied and the data used. Therefore, we will investigate this earthquake swarm further using cross-correlation between events.

With this dataset it might be possible to identify additional regional phases like sP, PmP or sPmP. Those could then be used in further research to improve estimation of hypocentral parameters for other events, where less data is available.

\section{The Supplement related to this article is available online at doi:10.5194/adgeo-36-77-2014-supplement.}

Acknowledgements. We would like to thank ZAMG, TU, ORFEUS and GeoRisk Earthquake Engineering for making available seismic data for this study. Topographic data used in maps was taken from SRTM (Jarvis et al., 2008) and historic seismicity from the Austrian Earthquake Catalog (ZAMG, 2014) before 2013. The ZAMGBulletin is available online via autodrm@zamg.ac.at. For picking the software Seismon by Mertl (2010) was used. Plots were created with ObsPy (Beyreuther et al., 2010).

\section{References}

Behm, M., Brückl, E., Chwatal, W., and Thybo, H.: Application of stacking and inversion techniques to three-dimensional wideangle reflection and refraction seismic data of the Eastern Alps, Geophys. J. Int., 170, 275-298, 2007a.
Behm, M., Brückl, E., and Mitterbauer, U.: A new seismic model of the Eastern Alps and its relevance for geodesy and geodynamics, VGI Österreichische Zeitschrift für Vermessung \& Geoinformation, 2, 121-133, 2007b.

Beidinger, A. and Decker, K.: 3D geometry and kinematics of the Lassee flower structure: Implications for segmentation ans seismotectonics of the Vienna Basin strike-slip fault, Austria, Tectonophysics, 499, 22-40, 2011.

Beyreuther, M., Barsch, R., Krischer, L., Megies, T., Behr, Y., and Wassermann, J.: ObsPy: A python toolbox for seismology, Seismol. Res. Lett., 81, 530-533, 2010.

Geller, R. J.: Scaling relations for earthquake source parameters and magnitudes, B. Seismol. Soc. Am., 66, 1501-1523, 1976.

Gutdeutsch, R., Hammerl, C., Mayer, I., and Vocelka, K.: Erdbeben als historisches Ereignis - Die Rekonstruktion des niederösterreichischen Erdbebens von 1590, Springer Verlag Wien, Heidelberg, New York, 1987.

Hintersberger, E., Decker, K., and Lomax, J.: Largest earthquake north of the Alps excavated within the Vienna Basin, Austria, in: European Seismological Commission (ESC) 32nd General Assembly, Montpellier, France, Abstract T/Sd2/TU/05., 2010.

Jarvis, A., Reuter, H., Nelson, A., and Guevara, E.: Hole-filled seamless SRTM data V4, available at: http://srtm.csi.cgiar.org (last access: 24 April 2014), 2008.

Kennett, B. L. N.: IASPEI 1991 seismological tables, Research School of Earth Sciences, Australian National University, 1991.

Lenhardt, W., Freudenthaler, C., Lippitsch, R., and Fiegweil, E.: Focal-depth distributions in the Austrian Eastern Alps based on macroseismic data, Austrian Journal of Earth Sciences, 100, 6679, 2007.

Lomax, A., Virieux, J., Volant, P., and Berge, C.: Advances in seismic event locations, chap. Probabilistic earthquake location in 3D and layered models: Introduction of a Metropolis-Gibbs method and comparison with linear locations, 101-134, Kluwer, Amsterdam, 2000.

Mertl, S.: Seismon, available at: http://www.stefanmertl.com/ (24 April 2014), 2010.

Mertl, S. and Brückl, E.: ALPAACT seismological and geodetic monitoring of ALpine - PAnnonian ACtive Tectonics Annual Report - Research Year 2009, Tech. rep., Austrian Academy of Sciences, 2010.

Nagy, W.: New region-dependent travel-time handling facilities at the IDC; Functionality, testing and implementation details, Tech. Rep. 96/1179, SAIC, 1996.

Peresson, H. and Decker, K.: Far-field effects of Late Miocene subduction in the Eastern Carpathians: E-W compression and inversion of structures in the Alpine-Carpathian-Pannonian region, Tectonics, 16, 38-56, 1997.

ZAMG: Austrian earthquake catalogue of earthquakes from 1200 to 2013 A.D. (Austria), Computer file of earthquakes with Ml and defining picks $>=6, \mathrm{E}$, Zentralanstalt für Meteorologie und Geodynamik, 2014. 